\title{
Facing In-Group Immorality: Differentiating Expressed Shame from Expressed Guilt
}

\author{
Nicolay Gausel ${ }^{1}$ \\ ${ }^{1}$ Faculty of Health and Social Sciences, Centre for Emotion Research, Østfold University College, Fredrikstad, \\ Norway \\ Correspondence: Nicolay Gausel, Faculty of Health and Social Sciences, Centre for Emotion Research, Østfold \\ University College, 1757 Halden, Norway. E-mail: nicolay.gausel@hiof.no
}

Received: May 11, 2012 Accepted: June 12, 2012 Online Published: August 3, 2012

doi:10.5539/res.v4n4p1 URL: http://dx.doi.org/10.5539/res.v4n4p1

\begin{abstract}
Even though shame and guilt are two widely investigated emotions, there is no consensus on what people mean when they use the terms 'shame' and 'guilt'. Some researchers argue that they are indicators of focus. That is, shame means a bad self, while guilt means a bad behaviour (Tangney, 1991). However, other researchers have argued that shame and guilt must be understood in the context of 'the self' and 'the other'. Since shame is more unpleasant than guilt, people that feel shame scorn themselves in addition to the scorn that derives from a condemning imagined 'other'. This experience is so painful, that people would rather not allow shame to impact them personally; consequently they try to defend against it. One way to do this is to express guilt instead (Lewis, 1971). Building on this latter view, I will debate a new model as proposed by Gausel and Brown (2012) that argue if guilt and shame are evoked simultaneously in the face of immoral in-group behaviour, then people would allow guilt to address them personally, while shame will address their in-group. This means that guilt will motivate them to undo their personal self and their personal behaviour, while shame will motivate them to undo the in-group self and behaviour. Implications for intergroup research are discussed.
\end{abstract}

Keywords: shame, guilt, anger, self, behaviour, group, personal

\section{Introduction}

When in-group-members are confronted with factual information about immoral acts committed by their fellow group-members, they often react with feelings of shame and guilt (Brown, Gonzalez, Zagefka, Manci, \& Cehajic, 2008; Gausel \& Brown, 2012; Gausel, Leach, Vignoles, \& Brown, 2012). As an illustration, in early spring of 2008, Angela Merkel (the German chancellor) delivered a speech in Knesset, Israel, where she explained that her fellow countrymen were 'filled with shame' over the Holocaust. As a representative of the German state, she expressed a willingness to 'bow before the victims' and pledged eternal friendship with Israel (aljazeera.net, 2008). Even though it is well established that guilt and shame are typically expressed in these situations, there is less consensus on what people mean when they use these terms. Some researchers argue that expressions of guilt and shame are literal indicators of focus. That is, guilt should be understood as an expression of bad behaviour while shame as an expression of a bad self (e.g., Tangney, 1991). Others argue that they are indicators of appraised maturity versus childishness (e.g., Lewis, 1971), while others argue that they convey the same meaning and that there is no big difference (Iyer, Leach, \& Pedersen, 2004). Hence, there is no current consensus on what people mean when they use the terms shame and guilt.

In order to offer an alternative solution to the guilt/shame debate, I will highlight a recent model on in-group immorality and how members of this group deal with their expressed guilt and shame on a personal level versus a group-level (Gausel \& Brown, 2012). This personal versus group-level model of guilt and shame is based on the understanding of these two emotions as proposed by Helen Block Lewis (1971). The Gausel and Brown (2012) model, however, argue that in the face of in-group immorality, expressions of guilt will impact the personal self, while expressions of shame will impact the in-group self. This new approach to group-level immorality and the feelings of shame and guilt is important, because a very popular distinction between shame and guilt that was derived from a therapeutic work-method (e.g., Tangney, 1991; Tangney \& Dearing, 2002) has been copied into a literal semantic meaning of specific focus, which has then been used to understand what people mean when they report feeling shame and guilt. This direct transition has currently brought the understanding of shame and guilt to a halt. In the following, I will explain why. 


\section{The Moral Emotions: Shame and Guilt}

Even though shame and guilt have been drawing attention in the social sciences for over a decade, the two emotions have proven hard to disentangle (e.g., Gausel \& Brown, 2012; Leach, Iyer, \& Pedersen, 2006). This is probably because shame and guilt often surface simultaneously in the wake of immorality (Gausel \& Leach, 2011; Tangney, Miller, Flicker, \& Barlow, 1996), and due to this they are both associated with intense self-criticism for the failure (Gausel \& Brown, 2012; Gausel \& Leach, 2011; Lewis, 1971; Tangney \& Dearing, 2002). Perhaps therefore, they are often used interchangeably when people try to explain what they feel (Lewis, 1971; Tangney \& Dearing, 2002). Consequently, some research teams have come to the conclusion that there is no difference between shame and guilt, as they convey the same meaning (e.g., Iyer et al., 2004).

Despite these shared similarities, a lot of contemporary work on shame and guilt still draw a very sharp divide between the two emotions (Brown et al., 2008; Tangney et al., 1996; Tracy \& Robins, 2006). Currently, what seems to be the most popular distinction is the one of unequal foci (see Tangney, 1991; Tangney \& Dearing, 2002; for a critical discussion of this distinction, see Gausel \& Brown, 2012). This view of shame and guilt normally goes like this: When people in emotional distress express shame, it means that they think: $I$ did this bad thing, therefore $I$ am bad. However, if they should express guilt, it means that they think: I did a bad thing therefore what I did was bad. Hence, the expression of shame is seen as a literal indicator of a bad self (but not bad behaviour), while guilt is seen as a literal indicator of a bad behaviour (but not bad self). Despite its popularity, this distinction has serious flaws when it comes to understanding what people mean when they feel shame and guilt. However, as this literal focus view (shame as literally meaning bad self versus guilt as meaning bad behaviour) that was presented by Tangney (1991) has reached wide popularity, I will address this view in order to better explain what will happen when in-group members are faced with their in-group immorality.

\section{The Lewis (1971) Model of Shame versus Guilt}

Helen Block Lewis (1971) is often referred to as promoting the idea that shame is about a bad self, and guilt about a bad behaviour (see for example, Brown et al., 2008; Tangney, 1991; Tangney \& Dearing, 2002). Part of the reason for this understanding could be that she mentioned that 'shame is about the self' (p.87) and guilt 'about something' (p.87, italics in original). However, there is no trace in her widely cited 1971 writing of a mentioning that shame = bad self (but not bad behaviour), while guilt = bad behaviour (but not a bad self). On the contrary, she underlined throughout her writings that guilt also involved a critical and unpleasant view of the self. Hence, this literal foci view does not represent the Lewis (1971) argument.

\subsection{Moral Failure as the Basis of Both Shame and Guilt}

Rather, for Lewis (1971) it was the position of 'the self' and 'the other' that made up her prominent distinction between shame and guilt. In her famous 1971 book; 'Shame and guilt in neurosis' she elegantly deployed microanalysis in order to investigate how the structure of 'the self' and 'the other' operate in feelings of shame and guilt with clients diagnosed with neurosis. According to Lewis, both shame and guilt are felt as a consequence of some moral failure that the client judge herself as being the cause of. Even though some failures eliciting shame do not appear moral per se - for example the failure to live up to ones academic potential or failure to be social - these are still transgressions of norms that the client interprets of moral importance for herself. Hence, Lewis (1971) argues that it is moral appraisals that ignite the feelings of shame and guilt.

\subsection{The Shame Experience}

According to Lewis (1971; for an overview, see her Table 1, p. 88 and Table 2. p. 90-91), the shame experience is often evoked after a moral failure that signals a deficiency in the self. When a failure is appraised in this way, then two core reflections dominate: 1. 'the self' becomes an object of scorn and 2. 'the other' becomes an object of scorn. In the first alternative when 'the self' becomes an object of scorn, then the position of the self becomes unable. It is experienced as paralyzed and childish; incapable of hindering or diminishing the intense self-criticism of scorn. However, this is not the only psychological problem for the shameful person; simultaneously, the shameful client imagines that a personalized 'other' condemns her. Hence, 'the other' is therefore also a source of scorn. This 'other' is active. It is adult and powerful. It ridicules the shameful person and condemns her for the moral failure that she has been responsible for. Thus, in the shame-experience, the client seems to be trapped under two different sets of appraisals where 'the self' is helpless and deficient without any means to hinder the imagined adult 'other' to condemn her, and therefore to abandon her childish self.

\subsection{The Guilt Experience}

The guilt experience is somewhat different, according to Lewis. It shares with shame that it is often ignited by a moral failure, and it shares the importance of 'the self' and 'the other' (for an overview, see Lewis, 1971; Table 1, p. 88 and Table 2. p. 90-91). However, in guilt 'the self' is able. Now, 'the self' is its own source of remorse and concern. It is therefore intact and responsible, and because of this, 'the self' is seen as adult. Simultaneously, 
'the other' is no longer personalized as an instigator. Instead, 'the other' is injured and hurt. Like with shame, the experience between the self and 'the other' is combined. The client appraises herself able and responsible for the pain inflicted on 'the other', and she is therefore filled with remorse and an adult sense of responsibility and control.

Hence, as both shame and guilt are painful affects for Lewis (1971), she distinguished shame from guilt on the basis of the role played by 'the self' and 'the other'. For shame, 'the self' is paralyzed, while 'the other' is condemning. For guilt, 'the self' is able and responsible, and 'the other' is hurt and injured. Consequently, the shame-experience is viewed as childish and highly unpleasant, while the guilt-experience is viewed as adult and unpleasant.

\section{4 'Childish' Shame and 'Mature' Guilt}

Due to the intense self-directed anger combined with the imagined and unpleasant condemnation from 'the other', shame is theorized to be associated with attempts at moving away from the shame-eliciting stimuli through denial, avoidance and suppression of the emotion shame itself (but see Gausel \& Leach, 2011; Gausel et al., 2012 for a contrasting view). This means that for Lewis (1971), shame is considered such a childish and painful emotion that it is something the client would rather not allow impacting herself. If anything, it is the adult guilt that she will allow to impact her personal self, leaving shame allocated to something to defend against. Hence, as guilt is considered a “more articulated experience than shame, and a more dignified one' (Lewis, 1971, p. 42), the client would rather prefer to express the 'mature' feeling of guilt, rather then the 'childish' feeling of shame. This is probably why Lewis argued that 'when shame and guilt are both evoked in response to a moral transgression, the two states tend to fuse with each other, and to be labelled 'guilt'” (p. 37). According to Lewis, it is precisely this that makes it difficult to discharge shame as it is often 'hidden' behind the less intense expressions of 'mature' guilt.

\section{The Tangney (1991) Model of Shame versus Guilt}

June Price Tangney is often referred to when the view of shame and guilt is dissociated on the basis of focus. Like Lewis (1971), Tangney (1991) hold the view that shame and guilt are elicited due to breach of moral norms and that they are unpleasant. However, unlike Lewis, Tangney (1991) argues that guilt has its focus on specific behaviour as distinct from the self, while shame has its focus on a globally bad self and that any immoral behaviour is swiftly generalized to the 'entire self' (605). Hence, for Tangney (1991, p. 605), the experience of guilt 'requires making a clear distinction between self and behaviour' where behaviour is 'related, but somewhat distinct from the self' (p. 605). This means, that Tangney (1991) view expression of shame as expression of global self-defectiveness, while expression of guilt is seen as expression of regrettable behaviour. Thus, it is theorized that when someone express their shame, it means that are thinking that they are a bad person, but if someone express their guilt, it means that they are thinking of their bad behaviour (Tangney, 1991; Tangney \& Dearing, 2002).

\section{1 'Ugly' Shame and 'Adaptive' Guilt}

As the self is globally defective in this model of shame, the shameful person is theorized to be preoccupied with herself leaving no room for empathic concern for 'the other', hurt person. Logically, Tangney (1991) therefore holds the view that shame is 'ugliness' (p. 606). On the other hand, as guilt is separated from 'the self' in this model, it has space for empathic concern for 'the other' hurt person. Thus, Tangney (1991) views guilt as an emotion that is actually not so 'bad after all' (p. 606). She therefore proposes that guilt is a more 'mature level of psychological development' (1991, p. 605). (Note 1) Not surprisingly, Tangney argues that the client should be encouraged to differentiate between who they are (shame) and what they do (guilt). That is, they should be explained the differences between shame $=$ bad self and guilt $=$ bad behaviour, so the client can 'make $a$ conscious shift' (Tangney \& Dearing, 2002, p. 176) from appraising themselves as a globally bad person, to the more behaviour oriented and adaptive guilt.

\subsection{Differentiating between Who You Are (Shame) and What You Do (Guilt)}

It is important to note that Tangney and Dearing (2002, p. 176) view it as necessary to 'explicitly educating the client about the difference between shame and guilt' as the clients are unaware of or 'have not really considered the difference between condemning a behaviour and condemning the self' (p. 176). The reason for this education is that Tangney et al., $(1991,1996,2002)$ point to the constructive sides of the therapeutic technique of differentiation between shame and guilt in this way. If the client can see that there is a difference between what 
she is and what she does, it is possible to start healing by challenging the perceptions that a moral failure indicates a globally, defective self and rather that it indicates a behaviour that can be changed.

\subsection{Difficulties with Receiving Empirical Support for the Tangney (1991) Model}

However, this therapeutic strategy is not the best of solutions if one wants to understand the meanings people attach to the emotion words they use (see Gausel \& Leach, 2011; Gausel et al., 2012; Gausel \& Brown, 2012). It is on this issue the Tangney model of guilt and shame as literal semantic carriers of foci-meaning fail. In fact, Tangney and Dearing (2002) openly debate this when they discuss their consistent failure to find support for their hypothesized differentiation. For example, when they specifically asked their own participants to rate 'blamed my actions and behaviour' and 'blamed my personality and my self' in conjunction with shame and guilt experiences (see Tangney et al., 1996; for a discussion of these results, see Tangney \& Dearing, 2002) they found no correlation between the feelings and the hypothesized foci. As a response to this failure, they argued that these blatant items were 'too abstract' for their participants (Tangney \& Dearing, 2002, p. 22). Even in secondary analyses their distinction failed to receive support: They found that 'the rating of blaming self versus blaming behaviour was uncorrelated with the degree to which participants wished they had acted differently, the degree to which they wanted to make amends (both behaviour-focused items), and the degree to which they felt disgusted with the self (a clearly self focused item)' (p. 22, italics in original). The failed support for their literal foci-meaning made them conclude that: 'the students really didn't understand the distinction we were trying to make' (p.22). Consequently, Tangney et al., draw the conclusion that it was simply 'too abstract for college undergraduates with little background in psychology' (p. 22) too understand this distinction.

\subsection{Shame and Guilt Does Not Differ in Foci}

Hence, even when Tangney and colleagues tried as best as they could to make their participants go along with their theorized distinction, the participants refused to do so. The participants did not attach a behaviour-focus to a guilt experience, or a self-focus to a shame experience. This is not surprising, because felt shame is often reported together with an appraisal that the self is defective (Gausel \& Brown, 2012; Gausel \& Leach, 2011; Gausel et al., 2012; Lewis, 1971) and together with a behaviour-critical view (Andrews, Quian, \& Valentine, 2002; Dresler-Hawke \& Liu, 2006; Gausel \& Brown, 2012; Gausel \& Leach, 2011). The same pattern can be observed with guilt: It is often reported together with appraised unjust or defective behaviour (Doosje, Branscombe, Spears, \& Manstead 1998; Iyer, Leach, \& Pedersen, 2004; Tangney \& Dearing, 2002) and a defective self (Lewis, 1971). Hence, the literal foci-distinction between shame and guilt that has been promoted by Tangney et al., $(1991,1996,2002)$ must be adjusted by the fact that shame and guilt does not differ in foci (for a general discussion, see Gausel \& Leach, 2011).

\section{The Gausel and Brown (2012) Model of Shame versus Guilt}

On the basis of the above, a logic question arises: Is it then impossible to disentangle shame from guilt? On a simple bad self versus bad behaviour, the answer must be no. But a distinction between the two can be obtained by noting that shame is more intensely self-critical than guilt (e.g. Gausel \& Leach, 2011; Lewis, 1971; Tangney et al., 1996; Tracy \& Robins, 2006). Shame makes you worry more about who you are as a person, than does guilt (e.g. Lansky, 1995; Lewis, 1971) and because of this, shame is closely related with distressing self-evaluation (e.g. Lewis, 1971), self-directed hostility (e.g. Gilbert \& Miles, 2000) and depression (e.g. Allan, Gilbert, \& Goss, 1994; Beck, Emery, \& Greenberg, 1985).

\subsection{Dealing with In-Group Immorality: Guilt and the Personal Self versus Shame and the In-Group Self}

As shame is known to have such a serious impact on the self, Lewis (1971) argued that people defend against it by trying to distance themselves from it, and remove it from their personal self-image by expressing guilt instead. However, feelings of shame are difficult to escape. Shameful people therefore acknowledge that they feel shame when they perceive the environment as safe and accepting (Rogers, 1961). However, in relation to in-group failures a window of opportunity to move away from the unpleasant shame is created. If a moral failure is committed by a group with which one shares an identification (see Taijfel \& Turner, 1986) then a possible alleviation could be to allow the 'mature' guilt to impact oneself, while the more 'unpleasant shame' impacts something outside of the personal self; i.e., the in-group-self. In line with Lewis (1971), Gausel and Brown (2012) therefore argue that as long as shame and guilt co-occur in the face of in-group immorality, people would rather let their expressions of guilt impact their personal self by wanting to undo their personal self and wanting to undo their personal behaviour. In contrast, people would try to let their expressions of shame impact something that does not directly refer to their personal self. Gausel and Brown (2012) therefore argue that in in-group situations, people would rather let shame impact their in-group-self by wanting to undo the in-group-self and wanting to undo the in-group-behaviour (see Figure 1). 


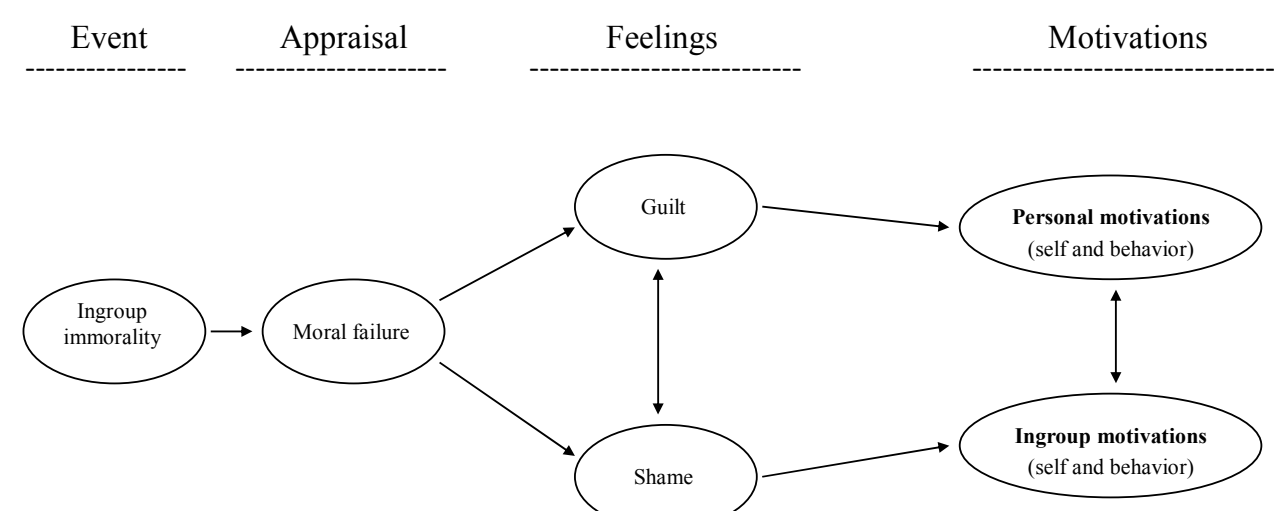

Figure 1. Relational model of in-group immorality, shame and guilt and personal vs. in-group undo motivations

\subsection{Reviewing Empirical Support}

In line with these claims, Gausel and Brown (2012) conducted a field study in a context where a majority group had committed grave moral failures against a minority group. They approached majority community members aboard ferries, trains and in public buildings. After having agreed to participate, they were presented with detailed information about the in-group abusive behaviour as an introductory part of a short questionnaire. The idea was to investigate how guilt and shame (and anger) related with responses of wanting to undo personal versus in-group self and behaviour. Gausel and Brown (2012) found substantial support for their hypotheses. As expected, the participants acknowledged that the abuse was a clear moral failure. Also as expected, the participants felt both shame and guilt in responses to this moral failure. However, the more guilt participants felt, the more they wanted to undo and change their personal self and behaviour (this was not true for their felt shame). As expected, guilt also predicted personal anger (but not in-group anger), and this personal anger partly mediated the link between guilt and personal motivation. In contrast to this, and in perfect support of their hypothesis, the more shame these participants felt, the more they wanted to undo and change their in-group self and behaviour (this was not true for their felt guilt). Also as expected, shame predicted in-group directed anger (but not personal anger), and this in-group directed anger partly mediated the link between shame and their in-group motivation. In fact, supplementary analysis demonstrated that if shame and guilt were allowed to predict only personal-anger and in-group-anger (with motivations excluded from the model), then guilt were the only significant predictor of personal-anger, $\beta=.36$, and shame were the only significant predictor of in-group-anger, $\beta=39$.

\subsection{Accounting for Both Personal and Group-Level Self}

Based on their reasoning and their results, Gausel and Brown (2012) suggested that when researchers and practitioners deal with people's emotional reactions to in-group behaviour, they might gain a clearer picture of the psychological experience if they also account for personal versus in-group levels of the self-concept. Gausel and Brown (2012) concluded that this approach might provide a better basis for predicting how people respond to their felt guilt and shame in the face of immoral in-group behaviour, as opposed to assuming that people have a specific focus of self versus behaviour in mind when they express their guilt and shame.

\section{Conclusion}

The emotions shame and guilt has attracted wide attention for decades in the social sciences. Still, there is no shared consensus on what people actually mean when they say they feel guilt or shame. A prominent view argues that when people experience shame, it means that they literally focus on their bad self, but if they experience guilt, it means that they literally focus on their bad behaviour (Tangney, 1991). Despite its popularity, it is difficult to find empirical support for this view. This is probably because people do not know that they are supposed to have specific foci-meaning when they express shame or guilt. In my view, it is reasonable to believe that this distinction of shame and guilt may serve a better role in a clinical setting where the client is specifically encouraged to differentiate between who they are and what they do (e.g., Beck et al., 1985; Tangney \& Dearing, 2002), than in understanding the meanings people attach to the emotion words they use in everyday life (for a discussion, see Gausel \& Leach 2011; Gausel et al., 2012). Another view proposed by Lewis (1971) argues that 
guilt is normally considered a more mature emotion than shame, and because of this people perceive this emotion as preferable to shame.

As there is little consensus on what is meant by 'shame' and 'guilt', Gausel and Brown (2012) have proposed a model that is consistent with the original view of Lewis (1971), but inconsistent with that of Tangney and colleagues $(1991,1996,2002)$. According to their model, if guilt and shame co-occur in response to an in-group moral failure, people will allow their feeling of guilt (as a more 'mature' emotion) to impact their personal self with responses that critically address the self and the behaviour of the person. However, their feeling of shame (unpleasant as it is) will be directed against their in-group together with responses that critically address the in-group-self and the in-group-behaviour. Hence, when people report feeling guilt due to a moral failure committed by their in-group it means that they most likely are ready to activate a personal response. If people report feeling shame due to the same immorality, it means that they most likely activate an in-group response.

This would mean that when we as researchers and practitioners address moral failures on in-group levels, we should control for motivations on both a personal and in-group level in order to fully understand what people mean when they use the terms 'shame' and 'guilt'. Moreover, we should do this without being tempted to think that expression of guilt means that a person has a specific focus in mind (such as behaviour), that differs from when they express shame. Instead, we should account for how a person appraise the situation they are in (for example; how this relates to themselves and their in-group). Only then can we understand what a person means with the emotion words that they use (Gausel \& Leach, 2011).

\section{Acknowledgements}

The author would like to thank Lilliana del Busso.

\section{References}

Allan, S., Gilbert, P., \& Goss, K. (1994). An exploration of shame measures--II: psychopathology. Personality and Individual differences, 17, 719-722. http://dx.doi.org/10.1016/0191-8869(94)90150-3

Aljazeera, N. (2008). Germans 'feel shame' over Holocaust. Retrieved from http://english.aljazeera.net/News/aspx/print.htm

Andrews, B., Qian, M., \& Valentine, J D. (2002). Predicting depressive symptoms with a new measure of shame: The experience of shame scale. British Journal of Clinical Psychology, 41, 29-42 http://dx.doi.org/10.1348/014466502163778

Beck, A. T., Emery, G., \& Greenberg, R. L. (1985). Anxiety disorders and phobias: a cognitive approach. New York: Basic Books.

Brown, R., Gonzalez, R., Zagefka, H., Manzi, J., \& Cehajic, S. (2008). Nuestra Culpa: Collective guilt and shame as predictors of reparation for historical wrongdoing. Journal of Personality and Social Psychology, 94, 75-90. http://dx.doi.org/10.1037/0022-3514.94.1.75

Doosje, B., Branscombe, N. R., Spears, R., \& Manstead, A. S. R. (1998). Guilty by association: When one's group has a negative history. Journal of Personality and Social Psychology, 75, 872-886. http://dx.doi.org/10.1037/0022-3514.75.4.872

Dresler-Hawke, E., \& Liu, J. H. (2006). Collective shame and the positioning of German social identity. Psicologia Politica, 32, 131-153.

Gausel, N., \& Brown, R. (2012). Shame and guilt - do they really differ in their focus of evaluation? Wanting to change the self and behaviour in response to in-group immorality. The Journal of Social Psychology. http://dx.doi.org/10.1080/00224545.2012.657265

Gausel, N., \& Leach, C. W. (2011). Concern for self-image and social-image in the management of moral failure: Rethinking shame. European Journal of Social Psychology, 41, 468-478. http://dx.doi.org/10.1002/ejsp.803

Gausel, N., Leach, C. W., Vignoles, V. L., \& Brown, R. (2012). Defend or repair? Explaining responses to in-group moral failure by disentangling feelings of shame, inferiority and rejection. Journal of Personality and Social Psychology, 102, 941-960. http://dx.doi.org/10.1037/a0027233

Iyer, A., Leach, C. W., \& Pedersen, A. (2004). Racial wrongs and restitutions: The role of guilt and other group-based emotions. In N. R. Branscombe, \& B. Doosje (Eds.), Collective guilt: International perspectives (pp. 262-283). Cambridge, UK: Cambridge University Press.

Lansky, M. R. (1995). Shame and the scope of psychoanalytic understanding. American Behavioural Scientist, 38, 1076-1090. http://dx.doi.org/10.1177/0002764295038008004 
Leach, C. W., Iyer, A., \& Pedersen, A. (2006). Anger and guilt about in-group advantage explain the willingness for political action. Personality and Social Psychology Bulletin, 32, 1232-1245. http://dx.doi.org/10.1177/0146167206289729

Lewis, H. B. (1971). Shame and guilt in neurosis. New York: International Universities Press.

Rogers, C. (1961). On becoming a person. Boston: Houghton Mifflin.

Tajfel, H., \& Turner, J. C. (1986). The social identity theory of intergroup conflict. In S. Worchel, \& W. G. Austin (Eds.), Psychology of intergroup relations (pp. 7-24). Chicago, IL: Nelson-Hall.

Tangney, J. P. (1991). Moral affect: The good, the bad, and the ugly. Journal of Personality and Social Psychology, 61, 598-607. http://dx.doi.org/10.1037/0022-3514.61.4.598

Tangney, J. P., \& Dearing. (2002). Shame and guilt. New York: Guilford.

Tangney, J. P., Miller, S. R., Flicker, L., \& Barlow, D. H. (1996). Are shame, guilt, and embarrassment distinct emotions? Journal of Personality and Social Psychology, 70, 1256-1269. http://dx.doi.org/10.1037/0022-3514.70.6.1256

Tracy, J. L., \& Robins, R. W. (2006). Appraisal antecedents of shame and guilt: Support for a theoretical model. Personality and Social Psychology Bulletin, 32, 1339-1351. http://dx.doi.org/10.1177/0146167206290212

\section{Note}

Note 1. Note that even though Lewis (1971) holds that guilt is a more 'mature' emotion, she does not argue like Tangney, that it is mature because of a more mature psychological development; rather, she holds that clients view guilt as a less childish emotion. 